\title{
FLORÍSTICA E CONTINGENTE FITOGEOGRÁFICO DA VEGETAÇÃO ARBÓREA DO MORRO DO BOTUCARAÍ, RIO GRANDE DO SUL, BRASIL ${ }^{1}$
}

\author{
ALESSANDRO ABREU FÁVERO² SOLON JONAS LONGHI $^{3}$
}

\section{RESUMO}

A pesquisa avalia a influência das rotas migratórias do elemento arbóreo na florística de um remanescente da Floresta Estacional Subtropical em morro testemunho da região central do estado do Rio Grande do Sul. A amostra consiste de transectos contínuos, quinze unidades amostrais de $10 \times 50 \mathrm{~m}$, complementada pelo método do caminhamento aleatório. Na análise da vertente usaram-se as categorias topo, encosta-superior, meia-encosta, encosta-inferior e base, examinando-se, nestas, os processos geomorfológicos atuantes. Nas unidades amostrais registraram-se as árvores com circunferência à altura do peito igual ou maior a $15,7 \mathrm{~cm}$, medido a $1,30 \mathrm{~m}$ do nível do solo. Na análise da dissimilaridade usou-se o coeficiente de aglomeração (distância binária) e o agrupamento hierárquico (UPGMA). Obteve-se 1.196 árvores, 68 espécies, 56 gêneros e 30 famílias botânicas. Observou-se o predomínio de indivíduos e espécies ocorrentes em toda a área florestal do Estado, seguido por espécies limitadas ao extremo Noroeste (rios Paraná-Alto Uruguai) e por espécies limitadas à ala Leste (Torres até Santa Maria). Todavia, constatou-se uma diferença de representatividade do contingente fitogeográfico entre os segmentos de posição do relevo. Conclui-se que o morro possui heterogeneidade espacial que condiciona a florística e o contingente fitogeográfico. A vegetação arbórea do Morro do Botucaraí representa, para a Floresta Estacional Subtropical, uma diluição da Floresta do Alto Uruguai, enriquecida com elementos da Floresta Ombrófila Densa e, sobretudo, da Floresta Ombrófila Mista.

Palavras-chave: Biogeografia, Dendrologia, Ecologia de Paisagens, Euterpe edulis, Fluxos Florísticos.

\section{ABSTRACT}

[Floristics and phytogeographical contingent of arboreal vegetation in Botucarai Mountain, Rio Grande do Sul, Brazil].

The survey assesses the influence of the migratory routes of tree elements in the flora of a remnant of the Seasonal Subtropical Forest in a testimony mountain located in the central region of Rio Grande do Sul State. The sample consists of continuous transects, fifteen sample units of $10 \times 50 \mathrm{~m}$, supplemented by random transect method. In the analysis it was used the following categories: top, high-slope, half-slope, bottomslope and base, beeing examined the active geomorphological processes. In the sampling units, trees with circumference at breast height $(1.30 \mathrm{~m}$ above ground level) equal or greater than $15.7 \mathrm{~cm}$ were measured. The analysis of dissimilarity used the clustering coefficient (binary distance) and the hierarchical clustering (UPGMA). They were obtained 1.196 trees, 68 species, 56 genera and 30 botanical families. It was observed that predominate the number of individuals and species that exist in all state forest area, followed by species from the Northwest (Paraná-Alto Uruguay rivers) and the East wing (Torres to Santa Maria) of the state. However, it was recognized a difference of representativity of phytogeographic contingent between relief position segments. It is concluded that the mountain shows a spatial heterogeneity that affects the floristic and phytogeographical contingents. The tree vegetation at Botucarai Mountain is a Seasonal Subtropical Forest, mainly from the High Uruguay forest, enriched with elements of the Atlantic rain forest and, especially, the Araucaria forest.

Key words: Biogeography, Dendrology, Landscape Ecology, Euterpe edulis, floristics flow.

1 Recebido para publicação em 30/01/2015 e aceito para publicação em 28/02/2015.

2 Biólogo e Engenheiro Florestal, Mestre em Ciências Florestais (PPGEF), Universidade Federal de Santa Maria. Santa Maria, RS, BR. abreufavero@yahoo.com.br

3 Engenheiro Florestal, Dr. Professor do Departamento de Ciências Florestais, Universidade Federal de Santa Maria. Santa Maria, RS, BR. longhi.solon@gmail.com 


\section{INTRODUÇÃO}

Todas as características da vida na Terra, incluindo a distribuição geográfica das espécies e táxons superiores, foram influenciadas pela "história". É importante reconhecer que as características dos organismos contemporâneos foram moldadas pela história do lugar e da linhagem (Brown, 1995; Brown \& Lomolino, 2006).

A flora do Brasil insere-se no Reino Neotropical, o qual abrange a América do Sul, avança pela América Central até a península da Baja California (Hueck, 1972), e se estende do México ao sul da Flórida, estabelecendo contato com o Reino Holártico, até o extremo sul do Chile e Argentina, onde estabelece contato com o Reino Antártico (Marchiori, 2006). Atualmente, reune espécies de diferentes origens, que migraram ao longo dos períodos da geo-história continental, estando, assim, vinculada a flora africana, boreal e da Oceania (Leite, 2002).

Na síntese fitogeográfica da vegetação sulbrasileira, Klein (1984) admite que as flutuações climáticas recentes interferiram nos influxos e irradiações das espécies vegetais no Sul do Brasil; tal observação denota que as migrações da vegetação são antigas, caso da irradiação de gêneros andinos na Floresta Ombrófila Mista, que denota a expansão e recuo da Floresta nas bacias do Paraná e Uruguai (relictos encontrados na Floresta Ombrófila Densa), bem como a expansão e recuo da Floresta Ombrófila Densa e a expansão da Floresta Subtropical no subbosque da Floresta Ombrófila Mista.

O conhecimento da flora do Rio Grande do Sul, relacionado aos eventos geológicos e climáticos, são temas abordados por Rambo (1951a, b, 1953, 1954, 1956, 1961), que trata, entre outros assuntos de aspectos fitogeográficos, como: centros de origem, fluxos florísticos, rotas de migração e distribuição, e fisionomia da vegetação. Leite (2002) também aborda os diferentes momentos geohistóricos dos centros e fluxos florísticos, reconhecendo nove regiões fitoecológicas. Waechter (2002), por sua vez, aborda os padrões geográficos da flora atual em escala global (Cosmopolita, Holártico, Antártico, Pantropical, Anfipacífico, Anfiatlântico e Neotropical) e neotropical (Anfichaquenho, Atlântico, Chaquenho e Pampeano).

Conforme Marchiori (2006), a flora sul-riograndense inclui numeroso contingente Pantropical (América, África e sudeste asiático), reconhecendo, no contingente tropical, dois padrões geográficos: elementos Anfiatlânticos e Anfipacíficos.

Cabe ressaltar que a vegetação do Rio Grande do Sul é constituída de duas formações determinantes para a fisionomia vegetal - o campo e a floresta -, que se interpenetram e misturam (Rambo, 1956). Segundo o pesquisador, os campos rio-grandenses são formações climáticas e edáficas na sua origem, e relictos históricos ou manchas edáficas no tempo atual, devido ao clima favorecer a expansão das florestas, corroborando observação de Lindman (1906) sobre o avanço da floresta na região do campo devido a condições climatológicas favoráveis: elevada temperatura e umidade atmosférica.

A vegetação do Morro do Botucaraí inserese no remanescente da Floresta Estacional Subtropical do rebordo do Planalto Meridional. Neste sentido, compete recordar que na Era Cenozóica no Período Terciário, a cerca de 60 milhões de anos A.P., a ingressão marítima determinou a fisionomia do centro e sudeste do Estado. No centro, num corredor que vai do Oceano Atlântico até o Rio Uruguai, o mar destruiu e removeu a margem sul dos derrames melaríficos, da qual ficaram, como registros, apenas testemunhos em forma de tabuleiros isolados (Rambo, 1954).

Aproximadamente a 6 mil anos A.P. as características geográficas já se apresentavam com fisionomia similar à atual (Kern, 1991); no Holoceno, cerca de 8 mil anos A.P., a cobertura vegetal era de paisagens abertas e, sob clima seco, predominavam vegetais xerófilos. No "ótimo climático", segundo Bolzon \& Marchiori (2002), entre 5 e 4 mil anos A.P., a Floresta Subtropical se desenvolveu, tornando-se densa 
nas terras baixas do planalto e na encosta do rebordo do Planalto Meridional. As espécies florestais devem ter recolonizado os interflúvios, surgindo uma faixa contínua de vegetação e umidade na escarpa meridional do planalto sulbrasileiro (Kern, 1991).

O contingente fitogeográfico arbóreo tropical no Rio Grande do Sul irradiou-se por duas rotas migratórias (Rambo, 1961) a partir do centro costeiro de baixas latitudes, entre o Rio de Janeiro e o Sul da Bahia (Marchiori, 2006). A rota migratória da bacia fluvial do Paraná migrou pelo Alto Uruguai, seguindo pelos vales fluviais para o Sul e para o Leste; a outra rota migratória partiu da floresta costeira de Santa Catarina e entrou no Rio Grande do Sul pela "Porta de Torres", isto é, pela estreita passagem existente entre o rebordo do Planalto Meridional e o Oceano Atlântico (Rambo, 1961). Na encosta do Planalto Sul-Brasileiro, a norte da Depressão Central, essas duas correntes migratórias se interpenetram (Jarenkow \& Waechter, 2001).

No entanto, a contingência mesófila é a mais abrangente, pois determina a fisionomia da floresta até a Oeste de Santa Maria, alcançando o Litoral Norte, na região de Torres, além de ser localmente a mais antiga. Em relação à contingência higrófila, destaca-se que nenhum elemento arbóreo alcançou a região do Alto Uruguai, mas possui maior riqueza de espécies epífitas (Rambo, 1961).

Com base em Klein (1972), a Floresta Estacional Subtropical irradiou-se com elementos pioneiros, contornando a Serra Geral e a Serra do Mar, através da Depressão Central no Rio Grande do Sul, penetrando pela "Porta de Torres", em Santa Catarina, até alcançar o Morro dos Conventos e, inclusive, o baixo vale do Itajaí.

Segundo o pesquisador acima, a Floresta Ombrófila Densa manifestou a sua expansão no sentido austral ao longo do litoral e da encosta, alcançando o Rio Grande do Sul até os vales do Mampituba e do Maquiné. Alguns elementos penetraram na Floresta Estacional Subtropical, tais como as palmeiras Bactris lindmaniana (atualmente, B. setosa), Euterpe edulis, Geonoma schottiana, bem como Cytharexylum myrianthum, Dodonea viscosa, Faramea marginata, Guapira opposita, Hirtella hebeclada, Inga sessilis, Mimosa bimucronata, Myrcia glabra e Nectandra oppositifolia, entre outras.

Por conseguinte, a Floresta Estacional Subtropical do rebordo do Planalto Meridional no centro do Rio Grande do Sul constitui uma diluição da Floresta do Alto Uruguai, enriquecida com elementos da Floresta Ombrófila Densa e, sobretudo, da Floresta Ombrófila Mista (Klein, 1984).

A Floresta Estacional Subtropical no Rio Grande do Sul encontra-se arranjada em três regiões: o Alto Uruguai, o rebordo do Planalto Meridional e a Serra do Sudeste (Rambo, 1956; Hueck, 1972). Com base em Teixeira et al. (1986) e Veloso et al. (1991), as disjunções da Floresta Estacional Subtropical apresentam três formações: a Floresta Aluvial, que reveste os terraços aluviais na Depressão Central e no Planalto da Campanha Gaúcha, ao longo dos rios Jacuí, Ibicuí, Santa Maria, Uruguai e respectivos afluentes; a Floresta Submontana, que recobre a vertente sul do rebordo do Planalto Meridional, a Oeste do vale do rio Caí, estendendo-se sobre a borda do Planalto das Araucárias, nas áreas de relevo ondulado, além da bacia do rio Ijuí, no Planalto das Missões; e a Floresta Montana, que reveste áreas de relevo dissecado do rebordo do Planalto Meridional, nas partes elevadas das escarpas formadas pelo vale dos rios Taquari - Antas, limitando-se, nas cotas superiores, com a Floresta Ombrófila Mista.

De acordo com Kilca \& Longhi (2011), o termo "Floresta Estacional Subtropical" é oportuno para caracterizar a Floresta Subtropical do rebordo do Planalto Meridional, evitando, assim, o uso dos termos complementares "decídua" e "semidecídua", os quais têm causado grandes confusões e equívocos na caracterização desta floresta no Sul do Brasil, devido à carência de informações científicas e ao fato de 
que as mesmas são, predominantemente, secundárias.

Klein (1983) registrou 222 espécies arbóreas para a Floresta Estacional Subtropical no rebordo do Planalto Meridional; Brena \& Longhi (2002), na Quarta Colônia, relacionam 212 espécies; e Kilca \& Longhi (2011), para as imediações do rebordo, listaram 165 espécies.

A vegetação arbórea do Morro do Botucaraí, conforme o estudo fitossociológico de Longhi et al. (1986), está constituído de três comunidades arbóreas: a Floresta Submontana, a Floresta Montana de Encosta, e a Floresta do Cume ou Topo.

Neste contexto, a presente pesquisa tem o objetivo de avaliar as influências das rotas migratórias do elemento arbóreo na florística do Morro do Botucaraí, um remanescente da Floresta Estacional Subtropical, na região central do Rio Grande do Sul. Visa a caracterizar a florística e a contingência fitogeográfica da vegetação arbórea nos diferentes segmentos de posição de relevo, propondo-se a definir qual é o contingente fitogeográfico predominante em número de espécies e indivíduos, bem como examinar a dissimilaridade da vegetação arbórea nas diferentes posições de relevo.

\section{MATERIAL E MÉTODOS \\ Caracterização do local de estudo}

A pesquisa foi realizada na Floresta Latifoliada Estacional Subtropical Submontana de Cumeada (Oliveira-Filho, 2009), situada na encosta do rebordo do Planalto Meridional SulBrasileiro, na região central do Rio Grande do Sul, mais especificamente no Morro do Botu-

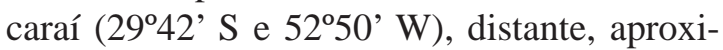
madamente, $6 \mathrm{~km}$ a sudoeste da cidade de Candelária.

A região é classificada no tipo de clima $\mathrm{Cfa}$, conforme Köppen, com precipitação média de $1.564 \mathrm{~mm}$ e temperatura média anual de $19,2^{\circ} \mathrm{C}$ (Moreno, 1961). Ferraz \& Roberti (2011), no rebordo do Planalto Meridional, avaliaram a precipitação e temperatura para os anos 2000 a 2004, constatando que: a precipitação possui distribuição uniforme, com chuvas fortes no fim do inverno e primavera; existem gradientes de temperatura sazonal e espacial do L para O; e a topografia é relevante para a temperatura. A precipitação pluviométrica, ao longo do ano, varia de 60 a $140 \mathrm{~mm}$ nos meses de verão, outono e inverno, e de 100 a $320 \mathrm{~mm}$ nos meses de primavera; a temperatura média no mês de janeiro atinge $24^{\circ} \mathrm{C}$, com máximas em torno de $40^{\circ} \mathrm{C}$; nos meses de inverno, a temperatura média é de $8^{\circ} \mathrm{C}$, sendo o mês de julho o mais frio, com ocorrência de geadas.

O solo da região é derivado de rochas efusivas básicas da Formação Serra Geral, ocorrendo derrames de lavas basálticas com incrustações de calcita. Pertence à unidade de mapeamento Charrua, caracterizada por solos rasos, de textura média, poucos desenvolvidos, moderadamente drenados, ligeiramente ácidos e neutros, com alta saturação de bases e sem problemas de alumínio trocável (Brasil, 1973). No Sistema Brasileiro de Classificação de Solo - SiBCs (Embrapa, 2006), a unidade de mapeamento Charrua compreende os Neossolos Regolítico Eutrófico Léptico e Litólico Eutrófico.

O Morro do Botucaraí, conhecido popularmente como "Cerro do Botucaraí", origina-se, provavelmente, do termo Ibytycaray, na língua Guarani, sendo, na atualidade, objeto de lendas sobre tesouros escondidos e de estudos sobre o "Santo Monge". Destaca-se, ainda, por ter sido visitado pelo botânico Friedrich Sellow, cujas coletas no local foram indicadas como In summo monte Botucurahy (Rambo, 1956).

Conforme Hintz (2006), ocorreram três ocupações históricas, como segue:

$1^{a}$ ocupação - magos e feiticeiros indígenas: os seus primeiros moradores não eram nada amistosos, nem seguidores da fé cristã. Índios bravios e magos feiticeiros ocupavam o morro e as redondezas, ainda no tempo das reduções, tendo verdadeiro ódio aos jesuítas.

$2^{\mathrm{a}}$ ocupação - jesuítas permanecem no morro até o retorno dos Bandeirantes: após a destruição da redução Jesus-Maria, o domínio do morro teria passado às mãos de jesuítas. Em 
1716, continuava nas imediações do morro a exploração dos ricos ervais por jesuítas e índios da redução Jesus-Maria. Neste mesmo ano, os bandeirantes paulistas vieram em busca de prata; no entanto, a tão cobiçada "prata" era apenas a erva-mate, ali beneficiada. Ao tentar escalar o morro, os invasores teriam sido atacados a tiros, por índios e jesuítas, fazendo-os recuar. A estrada ainda existente nas adjacências do morro era a rota por onde passavam carretas carregadas de erva-mate; esta teria sido, também, a rota dos tropeiros que se dirigiam ao Uruguai e à Argentina, ladeando o morro na encosta Sul. O local foi abandonado pelos jesuítas por volta de 1767, quando eles foram totalmente expulsos do território gaúcho.

$3^{\text {a }}$ ocupação - monge João Maria de Agostini: oitenta anos após, surge um novo pregador no morro, fundador de uma organização religiosa. O monge João Maria d'Agostini era originário de Piemonte, na Itália. A sua primeira estada no morro deu-se em 1846, quando teria se deslocado para o "Campestre", em Santa Maria, onde ele próprio intitulou-se solitário eremita do Botucaray. Perseguido pela milícia imperial, o monge teria retornado ao morro em 1849 para refugiar-se, sendo preso no local.

Por cerca de 1960, um audacioso projeto turístico começou a ser desenvolvido pela família Pertille, de Cachoeira do Sul, donos, na época, da Rádio Princesa do Jacuí, o chamado "Projeto do Bondinho", cujo objetivo era construir, em dois anos, um complexo turístico no cume do morro, incluindo a instalação da Rede TV Princesa.

Nos dias atuais, muitos são os que procuram o morro para pagamento de promessas e pedidos de curas nas águas de sua fonte. O misticismo que envolve o morro tem variadas origens religiosas. A primeira é da crença anticristã, cultuada por índios pagãos, seguida da ocupação cristã católica e da seita individual, pregada por uma pessoa tida como santa e milagreira (o Santo Monge). Desse modo, não é de estranhar que a cultura do "Santo Cerro" (e da "pra- ta escondida") se perpetue no imaginário de muitas pessoas (Hintz, 2006).

No entanto, a maior riqueza do Morro do Botucaraí, além de sua paisagem natural e valor cultural, é o tesouro científico representado por sua flora e fauna, além do patrimônio paleontológico, uma vez que existem registros de fósseis nas cercanias, como o Guaibassaurus candelarensis (Bonaparte, 1999), descoberto pela fundação Zoobotânica do Rio Grande do Sul em 1996, além de Gimnospermas fósseis.

O Morro do Botucaraí tem seu ponto mais alto à cerca de 570 metros de altitude sobre o nível do mar (Figura 1), lembrando, segundo o botânico e fitogeógrafo Balduino Rambo:

"Um castelo truculento de rochedos, com uma grande variabilidade de aspecto e descrevese que visto ao norte parece um único pilar rochoso, estreito e truncado; visto de Santa Cruz, apresenta-se como largo tabuleiro de regular declividade; visto do sul, transformase em estreita aresta, uniformemente inclinada sobre a planície.

Voando de avião ao redor descobre-se a sua verdadeira forma: em sentido Leste-Oeste, aparecem as faces compridas da aresta, fracamente inclinadas na base, verticais deste o terço de altura em diante; em sentido SulNorte, aparece a face curta, produzindo a impressão de longa aresta; em direção NorteSul apresenta-se a parte mais alta do norte, onde os paredões são mais elevados e íngremes" (Rambo, 1956, p. 342).

\section{Amostragem}

A amostra dos dados consistiu de quinze unidades amostrais de $10 \times 50 \mathrm{~m}$, subdivididas em subunidades amostrais de $10 \times 10 \mathrm{~m}$, perfazendo $7.500 \mathrm{~m}^{2}$, dispostas em transectos contínuos (Mueller-Dombois \& Ellenberg, 1974) no sentindo NE - SE.

Para avaliar a vertente do Morro do Botucaraí, usou-se a classificação de Cavalcanti (2014), que incide nas seguintes categorias: topo, encosta-superior, meia-encosta, encostainferior e base (Figura 2). 


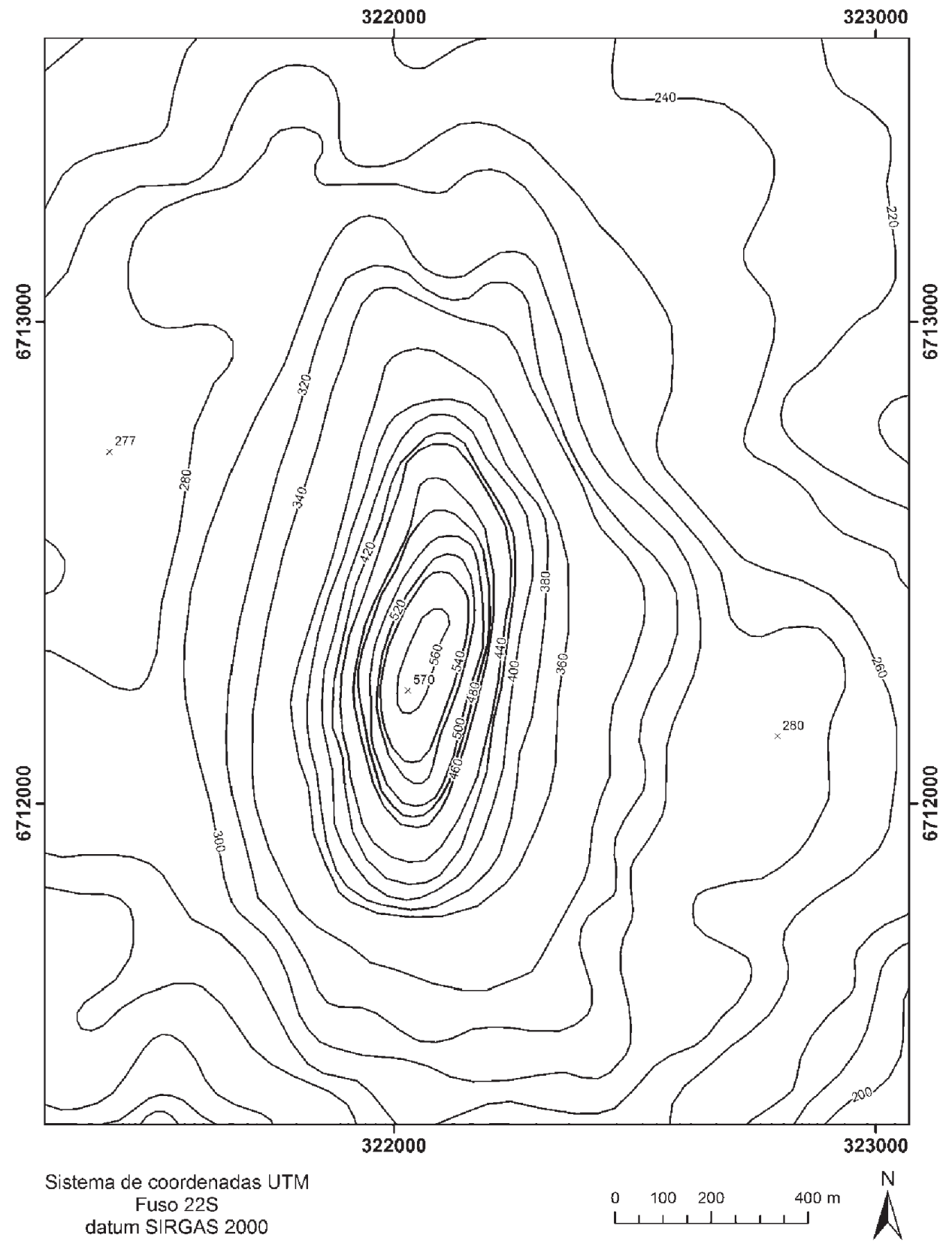

FIGURA 1 - Planta altimétrica do Morro do Botucaraí, na Depressão Central, próximo ao rebordo do Planalto Meridional do Rio Grande do Sul. 
Foram alocadas quatro unidades amostrais $\left(2.000 \mathrm{~m}^{2}\right)$ no topo, duas $\left(1.000 \mathrm{~m}^{2}\right)$ na encostasuperior, três $\left(1.500 \mathrm{~m}^{2}\right)$ na meia-encosta, duas $\left(1.000 \mathrm{~m}^{2}\right)$ na encosta-inferior e quatro $(2.000$ $\mathrm{m}^{2}$ ) na base. Nestas, examinou-se o perfil das unidades de vertente de Darlymple et al. (1968) (Christofoletti, 2011), que divide e caracteriza as unidades de perfil de relevo em função da declividade e dos processos morfogenéticos dominantes e atuantes (Tabela 1).
Os valores de altitude foram obtidos nas subunidades amostrais, registrando-se os valores nas arestas e no centro, para, em seguida, obter o valor médio; usou-se aparelho digital de Sistema de Posicionamento Global (GPS). Os valores de declividade da área foram obtidos para cada lado das subunidades amostrais, em graus de inclinação, obtendo-se, após, a média de inclinação; usou-se hipsômetro digital Vertex III.

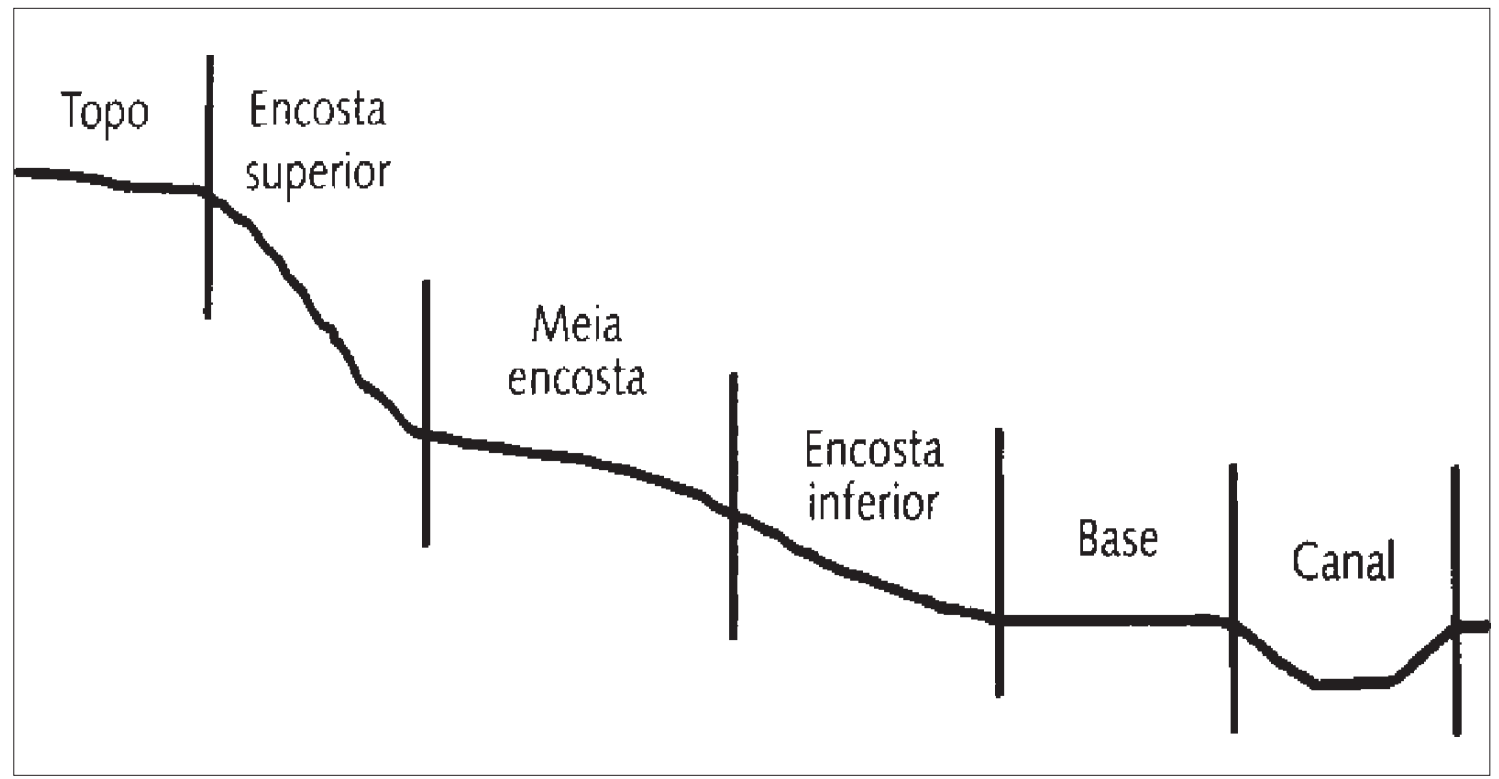

FIGURA 2: Diferentes posições dos segmentos de relevo (Cavalcanti, 2014).

\begin{tabular}{l|l}
\hline Unidades de vertentes & \multicolumn{1}{l}{ Processos geomorfológicos dominantes } \\
\hline Interflúvio $\left(0^{\circ}-1^{\circ}\right)$ & $\begin{array}{l}\text { Processos pedogenéticos associados a movimento vertical da } \\
\text { água superficial } \\
\text { Eluviação mecânica e química pelo movimento lateral da água } \\
\text { superficial }\end{array}$ \\
$\begin{array}{l}\text { Declividade com infiltração } \\
\left(2^{\circ}-4^{\circ}\right)\end{array}$ & $\begin{array}{l}\text { Formação de terracetes } \\
\text { Declive Convexo com Reptação } \\
\text { mecânico }\end{array}$ \\
Escarpas (ângulo maior de $\left.45^{\circ}\right)$ & $\begin{array}{l}\text { Transporte de material pelos movimentos coletivos do solo, ação } \\
\text { da água superficial e subsuperficial }\end{array}$ \\
Declives Intermediários de & $\begin{array}{l}\text { Reposição do material pelos movimentos coletivos e escoamento } \\
\text { superficial }\end{array}$ \\
Transporte & $\begin{array}{l}\text { Deposição a luvial, processos de movimento subsuperficial da } \\
\text { água } \\
\text { Sopé Coluvial }\left(26^{\circ}-35^{\circ}\right)\end{array}$ \\
Declividade aluvial $\left(0^{\circ}-4^{\circ}\right)$ & Transporte de material para a jusante pela ação da água \\
\hline Margem do Curso de Água & \\
Leito Curso de Água &
\end{tabular}




\section{Coleta de dados}

Nas unidades amostrais registraram-se os dados de árvores com circunferência à altura do peito maior ou igual a $15,7 \mathrm{~cm}$, medido a 1,30m do nível do solo. A CAP (circunferência à altura do peito) foi obtida com trena métrica. A amostragem de espécies foi complementada pelo método de caminhamento aleatório, registrando-se todas as espécies lenhosas encontradas. As árvores foram identificadas in loco, coletando-se o material botânico das espécies duvidosas para posterior identificação. A classificação das famílias botânicas segue o critério do Angiosperm Phylogeny Group (APG III, 2009) e, para gêneros e espécies, a Lista de Espécies do IPNI - The International Plant Names Index (2012) (http://www.ipni.org [acessado em 27 de março 2015]).

\section{Análise dos Dados}

$\mathrm{Na}$ avaliação do contingente fitogeográfico do elemento arbóreo seguiu-se a metodologia de Jarenkow \& Waechter (2001), adaptada de Rambo (1961), subsidiada pelas pesquisas de Klein (1984), Budke et al. (2004), Lindenmaier \& Budke (2006) e Sühs et al. (2010).

As espécies foram classificadas nos seguintes contingentes fitogeográficos (Rambo, 1961): espécies existentes em toda a área florestal do Estado (EAD); espécies limitadas à ala Leste do Estado (Torres até Santa Maria - ATL); e espécies limitadas ao extremo Noroeste do Estado (rios Paraná-Alto Uruguai - BPU).

$\mathrm{Na}$ análise de dissimilaridade da vegetação arbórea entre unidades amostrais, nos diferentes segmentos de posição de relevo, utilizou-se o coeficiente de aglomeração, valendo-se, para isso, da distância binária. Para a análise de cluster de agrupamento hierárquico usou-se o agrupamento por médias não ponderadas (UPGMA), que computa a média de dissimilaridade ou distância entre objetos a cada elemento do grupo, sendo que todos os objetos recebem o mesmo peso (Valentin, 2012; Borcard et al., 2011; Gotelli \& Ellison, 2011). Para a análise do teste de significância do cluster apli- cou-se o procedimento de bootstrapping (reamostragem $=1.000$ replicações), a fim de randomizar grupos e clusters, permitindo determinar a significância das várias "quebras" no dendrograma. O Processamento dos dados foi realizado com o programa $\mathrm{R}$ ( $\mathrm{R}$ Development Core Team, 2012), valendo-se dos pacotes Vegan e pvclust (Oksanen et al., 2012).

\section{RESULTADOS}

Foram registradas 1.196 árvores em 7.500 $\mathrm{m}^{2}$ de área amostral, e identificadas 68 espécies, distribuídas em 56 gêneros e 30 famílias botânicas. Por sua riqueza de espécies, destacaram-se Euphorbiaceae, Fabaceae e Myrtaceae (6 espécies), seguidas por Lauraceae (5 spp.), Meliaceae, Salicaceae, Sapindaceae (4 spp.) e Boraginaceae (3 spp.). Observou-se que 8 famílias botânicas estão representadas por 2 espécies e 14 famílias botânicas por apenas 1 espécie. A ordem de famílias botânicas com maior riqueza de gêneros inicia-se com Euphorbiaceae e Fabaceae (6 gêneros), seguidas por Lauraceae, Meliaceae, Myrtaceae, Salicaceae, Sapindaceae (3 gêneros), Arecaceae, Moraceae, Phytolaccaceae, Piperaceae, Solanaceae e Urticaceae (2 gêneros); as demais, estão representadas por apenas 1 gênero (Tabela 2).

O gênero com maior riqueza de espécies é Eugenia (4 spp.), seguido por Cordia (3 spp.), Allophylus, Annona, Casearia, Chrysophyllum, Myrsine, Nectandra, Ocotea e Trichilia, (2 spp.); os demais, estão representados por apenas 1 espécie.

A florística de algumas famílias botânicas e gêneros foi incrementada pelo registro de espécies encontradas fora das unidades amostrais e não contempladas pelo critério de inclusão; desse modo, constatou-se a ocorrência das seguintes espécies arbóreas: Banara parviflora (A. Gray) Benth. (Salicaceae) (EAD), Citharexylum montevidense Moldenke (Verbenaceae) (EAD), Dalbergia frutescens (Vell.) Britton (Fabaceae) (BPU), Dasyphyllum spinescens (Less.) Cabrera (Asteraceae) (BPU), Eugenia uniflora L. 
TABELA 2 - Florística, número de indivíduos e contingente fitogeográfico da vegetação arbórea do Morro do Botucaraí.

Diferentes posições de relevo $(\mathrm{Ba}=$ base, E.I. $=$ encosta-inferior, M.E. $=$ meia-encosta, E.S. $=$ encostasuperior, To $=$ topo $)$; C.F $=$ Contingente Fitogeográfico $(A T L=$ Floresta Ombrófila Densa, BPU $=$ Floresta Estacional Paraná-Alto Uruguai, EAD = ampla distribuição geográfica); $\quad \Sigma=$ somatório do número de indivíduos.

\begin{tabular}{|c|c|c|c|c|c|c|c|}
\hline Família e Espécie & $\mathrm{Ba}$ & E.I. & M.E. & E.S. & To & $\Sigma$ & C.F. \\
\hline Anacardiaceae & & & & 2 & & 2 & \\
\hline Lithraea brasiliensis Marchand & & & & 2 & & 2 & $\mathrm{EAD}$ \\
\hline Annonaceae & & 1 & & 1 & 2 & 4 & \\
\hline Annona neosalicifolia $\mathrm{H}$. Rainer & & 1 & & 1 & 1 & 3 & BPU \\
\hline Annona rugulosa (Schltdl.) H.Rainer & & & & & 1 & 1 & BPU \\
\hline Araliaceae & 2 & & & & & 2 & \\
\hline Schefflera calva (Cham.) Frodin \& Fiaschi & 2 & & & & & 2 & BPU \\
\hline Arecaceae & 11 & & & 2 & 3 & 16 & \\
\hline Euterpe edulis Mart. & 11 & & & & 2 & 13 & ATL \\
\hline Syagrus romanzoffiana (Cham.) Glassman & & & & 2 & 1 & 3 & EAD \\
\hline Boraginaceae & 1 & 4 & 2 & 3 & 3 & 13 & \\
\hline Cordia americana (L.) Gottschling \& J.S.Mill. & & 2 & 2 & & & 4 & $\mathrm{BPU}$ \\
\hline Cordia ecalyculata Vell. & & & & 2 & 1 & 3 & $\mathrm{BPU}$ \\
\hline Cordia trichotoma (Vell.) Steud. & 1 & 2 & & 1 & 2 & 6 & EAD \\
\hline Cannabaceae & 1 & & & & & 1 & \\
\hline Celtis iguanaea (Jacq.) Sarg. & 1 & & & & & 1 & BPU \\
\hline Cardiopteridaceae & & & & 1 & & 1 & \\
\hline Citronella paniculata (Mart.) R.A.Howard & & & & 1 & & 1 & EAD \\
\hline Celastraceae & & & & 1 & & 1 & \\
\hline Schaefferia argentinensis Speg. & & & & 1 & & 1 & $\mathrm{BPU}$ \\
\hline Ebenaceae & & 1 & & 6 & 2 & 9 & \\
\hline Diospyros inconstans Jacq. & & 1 & & 6 & 2 & 9 & $\mathrm{BPU}$ \\
\hline Euphorbiaceae & 96 & 9 & 23 & 46 & 130 & 304 & \\
\hline Actinostemon concolor (Spreng.) Müll.Arg. & 85 & 5 & 14 & 25 & 105 & 234 & EAD \\
\hline Alchornea triplinervia (Spreng.) Müll.Arg. & 2 & 1 & & & 5 & 8 & EAD \\
\hline Pachystroma longifolium (Nees) I.M.Johnst. & 6 & 1 & 8 & 2 & 17 & 34 & ATL \\
\hline Sapium glandulosum (L.) Morong & 1 & & & & & 1 & EAD \\
\hline Sebastiania brasiliensis Spreng. & 1 & 2 & 1 & 19 & 3 & 26 & EAD \\
\hline Tetrorchidium rubrivenium Poepp. \& Endl. & 1 & & & & & 1 & EAD \\
\hline Fabaceae & 24 & 4 & 1 & 3 & 3 & 35 & \\
\hline Erythrina falcata Benth. & 1 & & & & & 1 & $\mathrm{BPU}$ \\
\hline Inga marginata Willd. & 18 & 2 & & 1 & 1 & 22 & $\mathrm{EAD}$ \\
\hline Machaerium paraguariense Hassl. & 1 & & 1 & & & 2 & BPU \\
\hline Myrocarpus frondosus Allem. & 3 & & & 2 & 2 & 7 & BPU \\
\hline Parapiptadenia rigida (Benth.) Brenan & & 2 & & & & 2 & BPU \\
\hline Senegalia bonariensis (Gillies) Seigler \& Ebinger & 1 & & & & & 1 & $\mathrm{BPU}$ \\
\hline Lamiaceae & & & & & 1 & 1 & \\
\hline Vitex megapotamica (Spreng.) Moldenke & & & & & 1 & 1 & EAD \\
\hline
\end{tabular}




\begin{tabular}{|c|c|c|c|c|c|c|c|}
\hline Família e Espécie & $\mathrm{Ba}$ & E.I. & M.E. & E.S. & To & $\Sigma$ & C.F. \\
\hline Lauraceae & 9 & 2 & 1 & 2 & 37 & 51 & \\
\hline Aionea saligna Meisn. & & & & & 4 & 4 & ATL \\
\hline Nectandra lanceolata Nees \& Mart. & & & & & 1 & 1 & BPU \\
\hline Nectandra megapotamica $\mathrm{Mez}$ & 9 & 2 & 1 & 2 & 13 & 27 & EAD \\
\hline Ocotea puberula (Rich.) Nees & & & & & 2 & 2 & EAD \\
\hline Ocotea silvestris Vattimo-Gil & & & & & 17 & 17 & ATL \\
\hline Meliaceae & 22 & 40 & 43 & 53 & 21 & 179 & \\
\hline Cabralea canjerana (Vell.) Mart. & 4 & & & & 4 & 8 & EAD \\
\hline Guarea macrophylla Vahl & 7 & 1 & & & 1 & 9 & EAD \\
\hline Trichilia claussenii C.DC. & 11 & 38 & 43 & 53 & 16 & 161 & BPU \\
\hline Trichilia elegans A.Juss & & 1 & & & & 1 & BPU \\
\hline Moraceae & 68 & 6 & 27 & 15 & 107 & 223 & \\
\hline Ficus luschnathiana Miq. & 1 & & & & 2 & 3 & EAD \\
\hline $\begin{array}{l}\text { Sorocea bonplandii (Baill.) W.C.Burger, Lanj. \& } \\
\text { Wess.Boer }\end{array}$ & 67 & 6 & 27 & 15 & 105 & 220 & EAD \\
\hline Myrtaceae & 10 & 21 & 21 & 56 & 18 & 126 & \\
\hline Campomanesia xanthocarpa O.Berg. & & & 1 & 6 & 1 & 8 & EAD \\
\hline Eugenia involucrata D.C. & 1 & & & & & 1 & BPU \\
\hline Eugenia ramboi D.Legrand & 2 & & & 1 & 8 & 11 & BPU \\
\hline Eugenia rostrifolia D.Legrand & 3 & 16 & 17 & 21 & 8 & 65 & BPU \\
\hline Eugenia uruguayensis Cambess. & & & 1 & 26 & 1 & 28 & EAD \\
\hline Myrcianthes pungens (O.Berg) D. Legrand & 4 & 5 & 2 & 2 & & 13 & BPU \\
\hline Nyctaginaceae & & & & 1 & & 1 & \\
\hline Pisonia ambigua Heimerl & & & & 1 & & 1 & EAD \\
\hline Phytolaccaceae & 1 & & 1 & & & 2 & \\
\hline Phytolacca dioica $\mathrm{L}$. & 1 & & & & & 1 & EAD \\
\hline Seguieria aculeata Jacq. & & & 1 & & & 1 & EAD \\
\hline Piperaceae & 1 & & & & & 1 & \\
\hline Piper gaudichaudianum Kunth ex. C.DC. & 1 & & & & & 1 & EAD \\
\hline Primulaceae & 1 & & & 1 & 10 & 12 & \\
\hline Myrsine loefgrenii (Mez) Otegui & 1 & & & 1 & 2 & 4 & BPU \\
\hline Myrsine umbellata Mart. & & & & & 8 & 8 & EAD \\
\hline Proteaceae & & & & 13 & 2 & 15 & \\
\hline Roupala montana Willd. & & & & 13 & 2 & 15 & EAD \\
\hline Rosaceae & & & 1 & & & 1 & \\
\hline Prunus myrtifolia (L.) Urb. & & & 1 & & & 1 & EAD \\
\hline Rubiaceae & & & & 1 & & 1 & \\
\hline Randia ferox DC. & & & & 1 & & 1 & EAD \\
\hline Rutaceae & & & & & 4 & 4 & \\
\hline Zanthoxylum petiolare A.St.-Hil. \& Tul. & & & & & 4 & 4 & BPU \\
\hline Salicaceae & 5 & 1 & & 15 & 11 & 32 & \\
\hline Banara tomentosa Clos & & 1 & & 2 & 1 & 4 & BPU \\
\hline Casearia decandra Jacq. & & & & 4 & & 4 & BPU \\
\hline Casearia sylvestris $\mathrm{Sw}$ & 4 & & & 5 & 10 & 19 & EAD \\
\hline Xylosma pseudosalzmanii Sleumer & 1 & & & 4 & & 5 & EAD \\
\hline
\end{tabular}




\begin{tabular}{l|c|c|c|c|c|c|c}
\hline \multicolumn{1}{c|}{ Família e Espécie } & Ba & E.I. & M.E. & E.S. & To & $\Sigma$ & C.F. \\
\hline Sapindaceae & 15 & 2 & 2 & 14 & 49 & 82 & \\
Allophylus edulis Radlk. ex. Warm. & 3 & 1 & & 2 & 7 & 13 & EAD \\
Allophylus guaraniticus Radlk. & 1 & & 1 & 2 & & 4 & BPU \\
Cupania vernalis Cambess. & 11 & 1 & 1 & 2 & 32 & 47 & EAD \\
Matayba elaeagnoides Radlk. & & & & 8 & 10 & 18 & EAD \\
Sapotaceae & 1 & 3 & 5 & 6 & 1 & 16 & \\
Chrysophyllum gonocarpum (Mart. \& Eichler ex. Miq.) & 1 & 2 & 4 & 6 & 1 & 14 & BPU \\
Engl. & & 1 & 1 & & & 2 & BPU \\
Chrysophyllum marginatum (Hook. \& Arn.) Radlk. & & & 1 & 1 & & 2 & \\
Simaroubaceae & & & 1 & 1 & & 2 & BPU \\
Picrasma crenata Engl. & 11 & & 1 & & 1 & 13 & \\
Solanaceae & 9 & & & & & 9 & BPU \\
Cestrum intermedium Sendtn. & 2 & & 1 & & 1 & 4 & EAD \\
Solanum sanctae-catharinae Dunal & 39 & 5 & 2 & & & 46 & \\
Urticaceae & 8 & 2 & & & & 10 & EAD \\
Boehmeria caudata Sw. & 31 & 3 & 2 & & & 36 & EAD \\
Urera baccifera (L.) Gaudich. & 318 & 99 & 131 & 243 & 405 & 1.196 & \\
\hline Total Geral
\end{tabular}

(Myrtaceae) (EAD), Erytrhoxylum deciduum A.St.-Hil. (Erytrhoxylaceae) (EAD), Ficus cestrifolia Schott ex. Spreng. (Moraceae) (ATL), Guapira opposita (Vell.) Reitz (Nyctaginaceae) (ATL), Maytenus aquifolium Mart. (Celastraceae) (EAD), Mollinedia schottiana Perkins (Monimiaceae) (ATL), Myrsine lorentziana Arechav. (Primulaceae) (EAD), Picramnia parvifolia Engl. (Picramniaceae) (EAD), Quillaja brasiliensis Mart. (Quillajaceae) (elemento andino), Ruprechtia laxiflora Meisn. (Polygonaceae) (EAD), Strychnos brasiliensis (Spreng.) Benth. (Loganiaceae) (EAD), Trema micranta (L.) Blume (Cannabaceae) (EAD), Trichilia catigua A.Juss (Meliaceae) (BPU) e Zanthoxylum rhoifolium Lam. (Rutaceae) (EAD).

Compete destacar, ainda, o registro de espécies arbustivas, tais como Cestrum strigillatum (Solanaceae) (EAD), Escallonia bifida Link \& Otto ex. Engl. (Escalloniaceae) (elemento andino), Hybanthus bigibbosus Hassl.
(Violaceae) (EAD), Kaunia rufescens (P.W.Lund ex. DC.) R.M.King \& H.Rob. (Asteraceae) (ATL), Piper amalago L. (Piperaceae) (EAD), Psychotria carthagenensis Jacq., Psychotria leiocarpa Mart., Psychotria suterella Müll.Arg. (Rubiaceae) (ATL), Solanum mauritianum Scop. (EAD), Vassobia breviflora (Sendtn.) Huntz. (Solanaceae) (EAD), e um morfotipo (não identificado); das Poaceae, Chusquea ramosissima Lindm. (EAD) e Merostachys multiramea Hack. (EAD).

As espécies com maior abundância foram: Actinostemon concolor (19\%), Sorocea bonplandii (18\%) e Trichilia claussenii (13\%), seguidas por Eugenia rostrifolia (5\%), Cupania vernalis (4\%), Pachystroma longifolium (3\%) e Urera baccifera (3\%), perfazendo $65 \%$ do total. Ressalta-se que 18 espécies estão representadas por apenas 1 indivíduo, correspondendo a $1 \%$ do total.

A vegetação arbórea nos diferentes segmentos de posição de relevo foi representada pelas 
espécies com maior abundância (Tabela 1). No topo, Actinostemon concolor (26\%), Sorocea bonplandii (26\%) e Cupania vernalis (8\%); na encosta-superior, Trichilia claussenii (21\%), Actinostemon concolor (10\%), Eugenia uruguayensis (10\%), Eugenia rostrifolia (9\%) e Sebastiania brasiliensis (8\%); na meia-encosta, Trichilia claussenii (33\%), Sorocea bonplandii (21\%) e Eugenia rostrifolia (13\%); na encosta-inferior, Trichilia claussenii (38\%) e Eugenia rostrifolia (16\%); e na base, Actinostemon concolor (27\%), Sorocea bonplandii (21\%), Urera baccifera (10\%) e Inga marginata $(6 \%)$.

As espécies presentes em todos os segmentos de posição de relevo foram: Actinostemon concolor, Chrysophyllum gonocarpum, Cupania vernalis, Eugenia rostrifolia, Nectandra megapotamica, Pachystroma longifolium, Sebastiania brasiliensis, Sorocea bonplandii e Trichilia claussenii. As famílias botânicas presentes em todos os segmentos de posição de relevo foram: Boraginaceae, Euphorbiaceae, Fabaceae, Lauraceae, Meliaceae, Moraceae, Myrtaceae, Sapindaceae e Sapotaceae.

Com relação à riqueza de espécies dos contingentes fitogeográficos, registraram-se 35 espécies $(51 \%)$ ocorrentes em toda área florestal do Estado (EAD), 29 espécies (43\%) limitadas ao extremo Noroeste do Estado, (rios ParanáAlto Uruguai - BPU) e 4 espécies (6\%) limitadas à ala Leste do Estado (Torres até Santa Maria - ATL).

A diversidade sobe para 86 espécies, se forem consideradas as árvores encontradas fora das unidades amostrais e do critério de inclusão, elevando o número de espécies com distribuição EAD a 47 (55\%), BPU a 32 (37\%) e ATL a 7 espécies ( $8 \%)$.

Com relação à abundância dos diferentes contingentes fitogeográficos, registrou-se, para as espécies que existem em toda área florestal do Estado (EAD), 791 indivíduos (66\%), seguidas por espécies limitadas ao extremo Noroeste (rios Paraná-Alto Uruguai - BPU), com 337 in- divíduos (28\%), e das espécies limitadas à ala Leste do Estado (Torres até Santa Maria - ATL), com 68 indivíduos (6\%).

A ocorrência de Aiouea saligna, Ficus cestrifolia, Guapira opposita, Mollinedia schottiana, Ocotea silvestris, Pachystroma longifolium e da palmeira Euterpe edulis (além de algumas espécies arbustivas), corrobora a teoria que pressupõe o influxo da rota migratória do elemento arbóreo da Floresta Ombrófila Densa para a região central do Rio Grande do Sul (Rambo, 1961; Klein, 1984). A ocorrência de Escallonia bifida (arbusto) e de Quillaja brasiliensis, por sua vez, representa o influxo da Floresta Ombrófila Mista (Klein, 1984).

Constatou-se que nos diferentes segmentos de posição de relevo predominam espécies encontradas em toda área florestal do Estado (EAD), seguida por espécies oriundas dos rios Paraná-Alto Uruguai (BPU), e das limitadas à ala Leste do Estado (Figura 3).

Ressalta-se que Roupala montana (EAD) foi registrada no topo e, principalmente, na encosta-superior. As espécies (ATL) Aiouea saligna e Ocotea silvestris ocorreram somente no topo. Euterpe edulis (ATL) ocorreu no topo e, principalmente na base. Pachystroma longifolium (ATL), por sua vez, encontra-se em todos os segmentos, nas diferentes posições de relevo.

Com relação ao número de indivíduos que representam as contingências geográficas, verificou-se na base, na encosta-superior e no topo, a predominância de espécies ocorrentes em toda área florestal do Estado (EAD); na encosta-inferior e meia-encosta, a predominância das espécies limitadas ao extremo Noroeste do Estado (rios Paraná-Alto Uruguai - BPU); os indivíduos das espécies limitadas à ala Leste do Estado (Torres até Santa Maria - ATL), por sua vez, predominaram no topo do morro (Figura 4).

$\mathrm{O}$ exame do dendrograma de agrupamento hierárquico da vegetação arbórea entre as unidades amostrais evidenciou a ocorrência de 3 grupos homogêneos (menor variabilidade dentro dos grupos) e 3 grupos distintos (maior vari- 


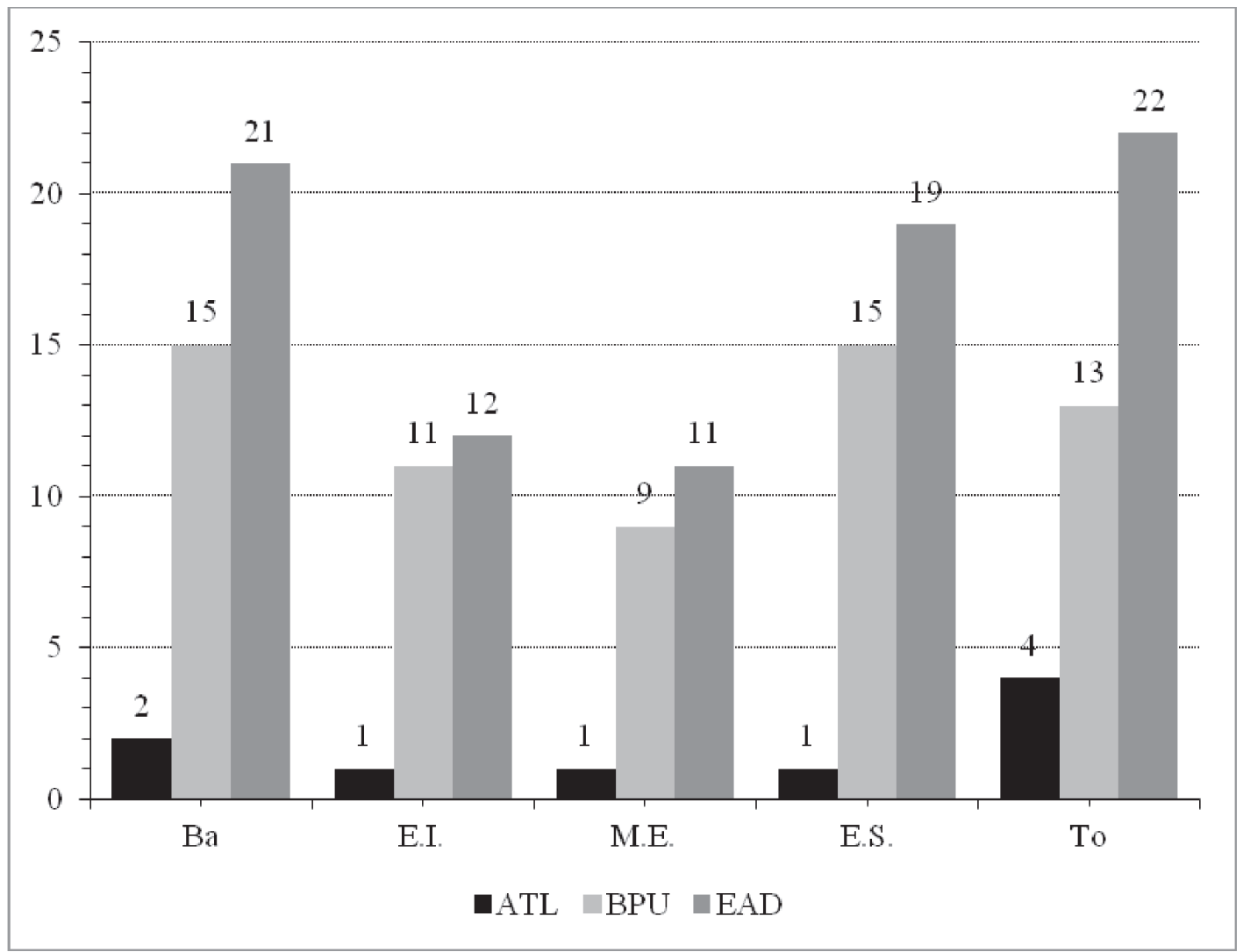

FIGURA 3 - Número de espécies da vegetação arbórea no Morro do Botucaraí, nos diferentes segmentos de posição do relevo.

Contingente Fitogeográfico (ATL = Floresta Ombrófila Densa; BPU = Floresta do Paraná-Alto Uruguai; EAD = ampla distribuição geográfica; PIN = Floresta Ombrófila Mista).

abilidade entre os grupos). De modo geral, as unidades amostrais nos mesmos segmentos de posição de relevo apresentaram menores dissimilaridades; desse modo, evidencia-se que a vegetação arbórea nas unidades amostrais do topo, seguido da meia-encosta e da base, é menos diferenciada. A vegetação arbórea nas unidades amostrais da base e topo, situadas em superfícies relativamente planas, se agruparam; a vegetação arbórea entre esses segmentos de posição de relevo, contudo, é relativamente dissimilar. Observou-se que a unidade amostral 11, na encosta-inferior, apresentou a menor dissimilaridade com as unidades amostrais da base (Figura 5).

As unidades amostrais da encosta-superior se encontram nas unidades de perfil de vertentes que se caracterizam pela ocorrência de declive convexo de reptação e de declividade intermediária de transporte (Tabela 1). As unidades amostrais da encosta-inferior se caracterizam pela ocorrência de escarpas. As unidades amostrais da meia-encosta se caracterizam pela ocorrência de escarpa e declividade intermediária de transporte. As unidades amostrais da base se caracterizam pela ocorrência do sopé coluvial, declividade intermediária de transporte e declividade aluvial. As unidades amostrais do topo, por sua vez, se caracterizam pela ocorrência de declividade com infiltração e declividade intermediária de transporte. Estas peculiaridades geomorfológicas dominantes e atuantes 


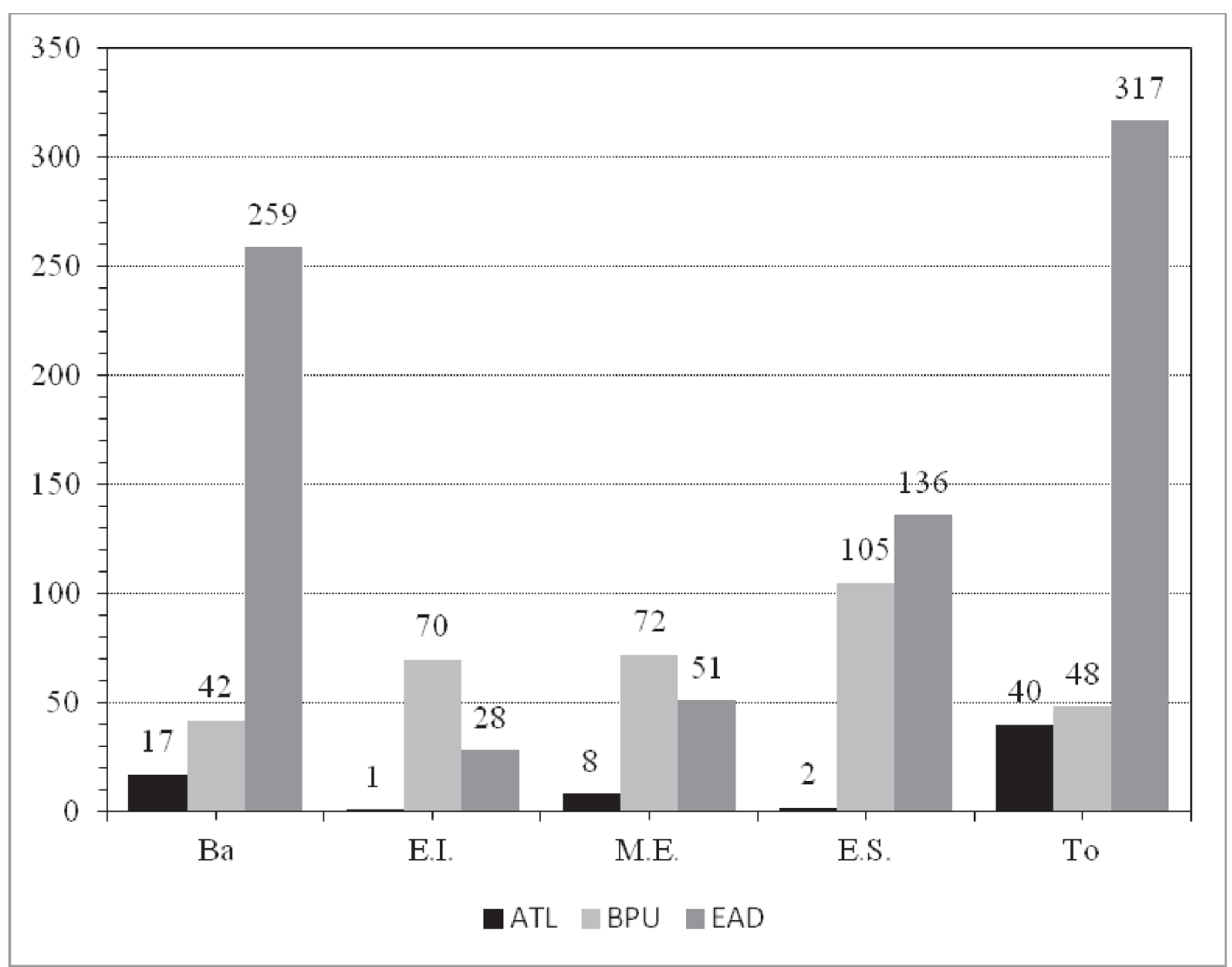

FIGURA 4 - Número de indivíduos da vegetação arbórea no Morro do Botucaraí, nos diferentes segmentos de posição do relevo.

Contingente Fitogeográfico $(\mathrm{ATL}=$ Floresta Ombrófila Densa; BPU = Floresta do Paraná-Alto Uruguai; EAD = ampla distribuição geográfica; PIN = Floresta Ombrófila Mista).

implicam na formação de diferentes subgrupos na vegetação arbórea, entre os diferentes segmentos de posição de relevo, devido às microrregiões e microclimas formados, além do gradiente de altitude.

\section{DISCUSSÃO}

$\mathrm{Na}$ análise das diferentes posições de segmentos de relevo observou-se a ocorrência de seis tipos de unidades de vertente, demonstrando, dessa maneira, a notável heterogeneidade espacial dos processos geomorfológicos atuantes. A diferenciação dessas unidades de perfil prevê a existência de zonas topográficas distintas nas diferentes posições de segmentos de re- levo e diferentes modos de migração geoquímica (Cavalcanti, 2014), originando distintos sítios paisagísticos, cuja vegetação arbórea possui fitossociologia espacial, fisionomia, florística e ecologia características.

A florística do Morro do Botucaraí, de modo geral, está em consonância com estudos realizados na região central do Rio Grande do Sul, por autores como: Longhi et al. (1986), Tabarelli (1992), Alberti et al. (2000), Longhi et al. (2000), Nascimento et al. (2000), Budke et al. (2005), Lindenmaier \& Budke (2006), Giehl et al. (2007), Sühs et al. (2010) e Fávero et al. (2011).

Com relação à composição de espécies, en- 


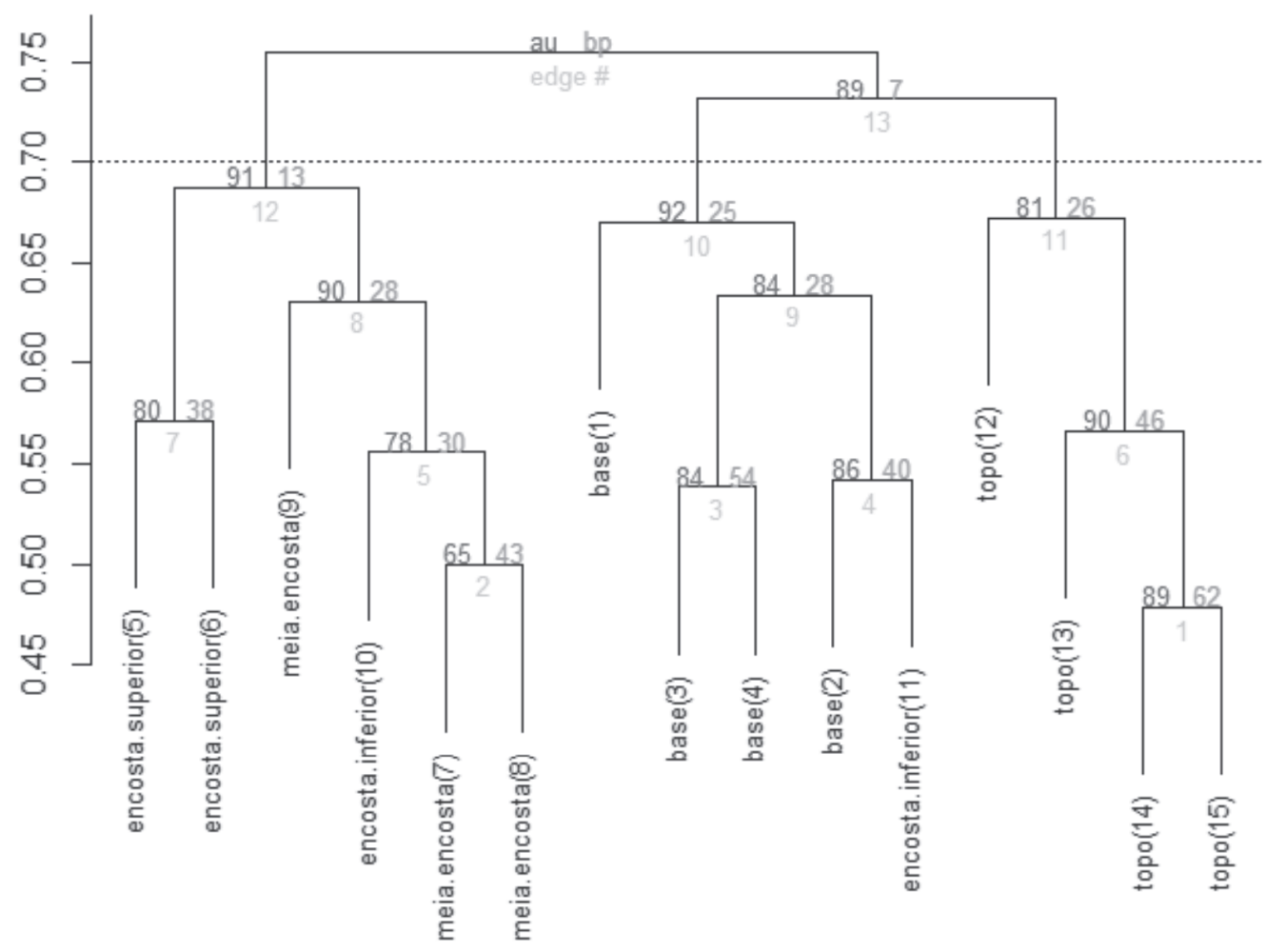

FIGURA 5 - Agrupamento de cluster (binário; UPGMA; p-values expresso por 1-p) da vegetação arbórea no Morro do Botucaraí, nos diferentes segmentos de posição do relevo.

$\mathrm{Au}=p$-value $; \mathrm{bp}=$ estimativa do bootstrap $;$ edge $=$ resultado imparcial do $p$-value.

tretanto, verificou-se diferenças importantes, sobretudo, nas famílias Fabaceae e Myrtaceae, que, juntamente com Euphorbiaceae, são as mais notáveis na composição da Floresta Estacional Subtropical, segundo Rambo (1980), Reitz et al. (1983), Klein (1984), Longhi et al. (1986), Alberti et al. (2000), Longhi et al. (2000), Jarenkow \& Waechter (2001), Araujo et al. (2004), Budke et al. (2004), Lindenmaier \& Budke (2006), Scipioni et al. (2009) e Sühs et al. (2010), entre outros.

A elevada riqueza específica de Fabaceae e Myrtaceae resulta, em parte, da ocorrência de espécies que se adaptaram a diferentes condições ambientais (Giehl, 2007). A família Myrtaceae é bem conhecida por sua elevada representatividade nas comunidades arbóreas do Rio Grande do Sul (Araujo et al., 2004; Budke et al., 2004; Budke et al., 2005; Giehl \& Jarenkow, 2008; Sühs et al., 2010; entre outros) e, conforme Sobral (2003), é a de maior distribuição geográfica e maior número de espécies na flora arbórea.

Segundo De Marchi \& Jarenkow (2008), a família Myrtaceae possui a maior riqueza de espécies em áreas mais a Leste do Estado; nas fraldas da Serra Geral, conforme Klein (1972), o número de espécies não é muito representativo, salientando-se Eugenia rostrifolia, sobretudo em solos úmidos do alto de encostas, como comprovado no presente estudo, e por Reitz et al. (1983) e Marchiori \& Sobral (1997), que in- 
dicam a preferência da espécie por sítios pedregosos e de solo raso. Conforme Reitz et al. (1983), trata-se de espécie amplamente dispersa pela Floresta Estacional do Alto Uruguai, pelas florestas da bacia do Jacuí, bem como na parte oriental do Escudo Rio-grandense, encontrando seu limite austral, possivelmente, no município de Pelotas; frequentemente está associada a Pachystroma longifolium.

Compete ressaltar, a seguir, as espécies Eugenia involucrata e Myrcianthes pungens (Klein, 1984); no presente estudo, entretanto, E. involucrata foi representada por apenas um indivíduo. A espécie, de acordo com Reitz et al. (1983), pode ser considerada rara e ocorre de forma esparsa no interior da floresta, habitando, segundo Marchiori \& Sobral (1997), principalmente a submata dos pinhais, as Florestas Estacionais do Alto Uruguai e Encosta da Serra Geral, bem como formações ciliares. Myrcianthes pungens, que prefere solos enxutos e pedregosos, foi encontrada em uma única escarpa, na encosta-inferior, apesar de ser espécie comum no alto de encostas (Marchiori \& Sobral, 1997) e topos de morros (Marchiori, 2009). Eugenia ramboi, em consonância com Klein (1972), mostrou-se pouco frequente, sendo encontrada em solos úmidos e pedregosos. Eugenia uruguayensis, espécie, em geral, de florestas próximas a rios, foi presentemente encontrada na encosta-superior. Por sua vez, Campomanesia xanthocarpa, em consonância com Marchiori \& Sobral (1997), apresentou maior abundância na encosta superior, em sítios úmidos.

A família Fabaceae, por sua vez, é representada por elevada riqueza de espécies que se irradiam, no Rio Grande do Sul, pela rota de migração dos rios Paraná e Uruguai (Rambo, 1961; Giehl, 2007, Jarenkow \& Waechter, 2001), sendo menos representadas no lado Leste da região central. No presente estudo, destacam-se Inga marginata e Myrocarpus frondosus. A primeira é predominante na baixada do morro, onde ocorrem as maiores perturbações antrópicas; tratase de espécie heliófila (pioneira), indiferente às condições do solo (Marchiori, 1997) e com vasta e regular dispersão pela Floresta Estacional do Alto Uruguai, do Alto do Ibicuí e, principalmente, das florestas da bacia do Jacuí, onde sobe pelos afluentes até 400-500m de altitude (Reitz et al. 1983). A segunda mostrou-se predominante, igualmente, na baixada do morro; conforme Reitz et al. (1983), é encontrada no fundo dos vales, no início das encostas e em outros locais de solos úmidos; de ampla dispersão na Floresta Estacional do Alto Uruguai, Rio Jacuí e Ibicuí, penetra no planalto, nas submatas dos pinhais, até altitudes de $600-800 \mathrm{~m}$, onde tornam-se raras.

A família Euphorbiaceae na região central do Rio Grande do Sul é representada, comumente, por Actinostemon concolor, Alchornea triplinervia, Gymnanthes klotzschiana e Sebastiania brasiliensis; no entanto, destaca-se no presente estudo, a ocorrência de Pachystroma longifolium, elemento arbóreo da Floresta Ombrófila Densa, observado em encostas ou solos rasos (Klein, 1984). A. triplinervia é espécie dependente da luminosidade e praticamente indiferente às condições físicas do solo (Markus \& Freitas, 2011); frequente na floresta do Alto Uruguai, fraldas da Serra Geral e Floresta Ombrófila Densa, ocorre, ainda, no Escudo Rio-grandense e na floresta do Alto Ibicuí, em altitudes de 300 a 500 metros (Reitz et al., 1983).

Entre as peculiaridades florísticas do morro salientam-se Euterpe edulis, Guapira opposita, Ocotea silvestris e Roupala montana, espécies que se encontram distribuídas, principalmente, na ala Leste do estado do Rio Grande do Sul.

No topo, bem como na encosta-inferior e na baixada do morro, registrou-se a ocorrência de Euterpe edulis, a qual representa o influxo de elementos botânicos da rota migratória da Floresta Ombrófila Densa para o interior do Rio Grande do Sul. Neste sentido, o Morro do Botucaraí deve proporcionar um refúgio ambiental para a espécie, que sofre efeitos antropogênicos, além de propiciar condições ambientais adequadas ao estabelecimento, de- 
senvolvimento, reprodução e dispersão de suas sementes.

A respeito da ocorrência de Roupala montana, constatou-se a presença da mesma na encosta-superior e topo, onde a temperatura deve ser menor do que na meia-encosta, na encosta-inferior e na baixada. A maior abundância, no entanto, foi encontrada na encosta-superior, onde outras variáveis ambientais, além da temperatura, interferem no estabelecimento e desenvolvimento. Segundo Marchiori (2006), essa espécie é nativa no Planalto sul-brasileiro, sobretudo em seu trecho Leste, próximo aos Aparados, estando vinculada à altitude e clima da região. De distribuição "anfipacífica" e restrita às montanhas do centro-leste brasileiro, os registros da espécie, no Rio Grande do Sul, apontam que a mesma está confinada a maiores altitudes (Giehl, 2007; Giehl \& Jarenkow, 2008; Kray, 2010; Bergamin et al., 2012) e, segundo Marchiori (2009), trata-se de um elemento do contingente extratropical, na Floresta Estacional.

De modo geral, a vegetação arbórea do subbosque está representada por Actinostemon concolor, Sorocea bonplandii e Trichilia claussenii, espécies exigentes, de ambientes com cobertura vegetal e pouca luminosidade para seu estabelecimento e desenvolvimento, motivo pelas quais são consideradas espécies clímax e típicas do sub-bosque (Vaccaro, 1997); devido à alta representatividade das mesmas no local de estudo, conclui-se que a vegetação arbórea encontra-se em fase de madureza. De acordo com Reitz et al. (1983), são arvoretas que constituem de 40 a $70 \%$ do sub-bosque, conferindolhe um aspecto de grande homogeneidade fitofisionômica.

A contingência fitogeográfica com maior riqueza de espécies e número de indivíduos está em consonância com estudos de Budke et al. (2004 - Santa Maria), Lindenmaier \& Budke (2006 - Cachoeira do Sul), Sühs et al. (2010 Rio Pardo) e Fávero et al. (2011 - Santa Maria). Sühs et al (2010), entretanto, registraram um maior número de espécies e indivíduos oriundos da Floresta Ombrófila Densa, comparados a outros estudos. Jarenkow \& Waechter (2001 - Vale do Sol), registraram, em sequência, espécies que existem em todo o Estado (EAD), seguido das oriundas da Floresta ombrófila Densa (ATL) e das espécies do rio Paraná-Alto Uruguai (BPU).

Com relação à rota migratória do ParanáAlto Uruguai (BPU), verificou-se uma expressiva representatividade na encosta-inferior e meia-encosta, devido, principalmente, à ocorrência de Trichilia claussenii e Eugenia rostrifolia. Conforme Rambo (1961), a participação dessa rota migratória é predominante na composição florística e fisionômica da Floresta Estacional Subtropical no centro do Rio Grande do Sul, tendo sido igualmente comprovado por Budke et al. (2004) e Lindenmaier \& Budke (2006).

Ao se analisar a ocorrência das espécies arbóreas do influxo da rota migratória Atlântica, verifica-se que Euterpe edulis encontra-se no seu limite austral. A espécie, no Brasil, possui ampla distribuição geográfica, ocorrendo desde Pernambuco até o Rio Grande do Sul; em direção ao centro do país, a espécie avança pelos vales dos rios Paraná e Iguaçu, ocorrendo, igualmente, na Argentina e Paraguai (Reis et al., 1996). No Rio Grande do Sul, ocorre na zona da Floresta Ombrófila Densa, compreendendo os municípios de Torres e Osório; ainda se irradia para Santo Antônio da Patrulha, Montenegro, Arroio do Meio, Lajeado, Santa Cruz do Sul, Guaíba e Barra do Ribeiro (Reitz et al., 1983).

Aiouea saligna, Ficus cestrifolia, Mollinedia schottiana, Ocotea silvestris e Pachystroma longifolium irradiam-se, ainda mais, no centro do Rio Grande do Sul. Com relação a Ocotea silvestris, presentemente registrada no topo do morro, também, ocorre no topo do Morro do Elefante, em Santa Maria, (Fávero et al. 2011). Essa espécie, raramente encontrada em estudos de composição florística e de fitossociologia espacial de comunidades arbóreas, foi assinala- 
da, até o presente momento, por Jarenkow \& Sobral (2000), Jarenkow \& Waechter (2001), Jurinitz \& Jarenkow (2003), Vargas \& Oliveira (2007), Marchiori (2009) e Markus \& Freitas (2011).

Ressalta-se a ocorrência de um indivíduo de Guapira opposita na baixada do morro; conforme Sobral et al. (2013) essa espécie é frequente nas comunidades arbóreas da encosta meridional da Serra Geral, na encosta da Serra do Sudeste e na Floresta Atlântica.

Conforme Rambo (1961) e Klein (1984), o elemento arbóreo da Floresta Ombrófila Densa se irradia sobre os domínios da Floresta Estacional Subtropical, favorecido pelas condições climatológicas atuais; todavia, esse influxo de migração do elemento arbóreo da Floresta Ombrófila Densa sofre as interferências das ações antrópicas, como perturbações e fragmentação dos ambientes naturais, além da extração ilegal, caso da palmeira Euterpe edulis, explorada para extração do seu meristema apical (palmito) e coleta de sementes.

A riqueza de espécies da rota migratória da Floresta Ombrófila Densa (ATL) no Morro do Botucaraí é expressiva, comparada aos estudos de Budke et al. (2004), Lindenmaier \& Budke (2006). Jarenkow \& Waechter (2001) e Sühs et al. (2010), autores que entretanto, registraram uma maior abundância de elementos dessa tipologia. Desse modo, esses estudos realizados em diferentes coordenadas geográficas permitem deduzir o efeito dos gradientes de continentalidade sob a florística e a estrutura ecológica da Floresta Estacional Subtropical, que estão relacionados aos gradientes ambientais, especialmente de temperatura e geomorfologia, corroborando os pressupostos teóricos de Rambo (1956; 1961) e Klein (1984).

Compete observar que a contingência fitogeográfica das espécies ocorrentes em todo Estado (EAD) condiciona, de forma marcante, as variações nas proporções dos elementos arbóreos das rotas migratórias e, desse modo, interferem na florística, na riqueza e na abundância de espécies e, consequentemente, na fitossociologia espacial e na estrutura ecológica da vegetação arbórea do morro. Segundo Scipioni et al. (2009), tal fato pode ser considerado um argumento referente ao recente avanço das florestas na região em estudo, e aos aspectos históricos antropogênicos.

Com relação aos elementos andinos, registrados na baixada no morro, na borda da vegetação arbórea entre a matriz de lavouras e de estradas, Rambo (1980) informa que eles são importantes na composição da Floresta Ombrófila Mista, inclusive em capoeiras. Conforme Waechter (2002), Escallonia bifida é Elemento Anfichaquenho e Quillaja brasiliensis é Elemento Neoantártico. Tratam-se de elementos extratropical, na Floresta Estacional (Marchiori, 2009).

Deste modo, o Morro do Botucaraí representa, para a Floresta Estacional Subtropical, a diluição das espécies arbóreas da rota migratória dos rios Paraná-Alto Uruguai, enriquecida com influxo das rotas migratórias da Floresta Ombrófila Densa e, sobretudo, da Floresta Ombrófila Mista, evidenciando, desse modo, o pressuposto teórico de Rambo (1961) e Klein (1984).

A baixa dissimilaridade dos grupos da vegetação arbórea demonstra uma baixa heterogeneidade na florística, devendo estar relacionado a aspectos compartilhados pelos diferentes segmentos de posição do morro, tais como a declividade intermediária de transporte, que gera microrregiões e microclimas similares, de modo a ser representada por três comunidades florestais, conforme Longhi et al. (1986).

\section{CONSIDERAÇÕES FINAIS}

O Morro do Botucaraí possui heterogeneidade espacial relevante para a vegetação arbórea, uma vez que sua geomorfologia pressupõe ambientes com variadas condições em um espaço geográfico restrito, gerando diversas microrregiões e microclimas, de modo a formar filtros para o estabelecimento e desenvolvimento das árvores, nos diferentes segmentos de posição do relevo. 
A florística foi pouco dissimilar entre os diferentes segmentos de posição de relevo, mas deduz-se que a vegetação arbórea deve apresentar características mais marcantes na estrutura ecológica e na fitossociologia espacial, originando distintas zonas ecológicas.

Constatou-se a predominância das espécies que ocorrem em toda a área florestal do Estado, seguida por espécies limitadas ao extremo Noroeste (rios Paraná-Alto Uruguai) e das espécies limitadas à ala Leste (Torres até Santa Maria). Mas, detectaram-se diferenças na representatividade do contingente fitogeográfico entre alguns segmentos de posição de relevo.

A vegetação arbórea do Morro do Botucaraí representa, para a Floresta Estacional Subtropical, uma diluição da Floresta do Alto Uruguai, enriquecida com os elementos da Floresta Ombrófila Densa e, especialmente, da Floresta Ombrófila Mista.

\section{REVISÃO BIBLIOGRÁFICA}

ALBERTI, L. F.; HIRT, J. A. N.; MACHADO JUNIOR, D. B. F.; STECKEL, M.; TOMBINI, C. S.; LONGHI, S. J. Aspectos florísticos e síndromes de dispersão das espécies arbóreas do morro de Santo Antão, Santa Maria-RS. Ciência e Natura, Santa Maria, v. 22, p. 145-160, 2000.

ANGIOSPERM PHYLOGENY GROUP III. An update of the Angiosperm Phylogeny Group classification for the orders and families of flowering plants: APG III. Botanical Journal of the Linnean Society, v. 161, p. 105-121, 2009.

ARAUJO, M. M.; LONGHI, S. J.; BRENA, D. A.; BARROS, P. L. C.; FRANCO, S. Análise de agrupamento da vegetação em um fragmento de Floresta Estacional Decidual Aluvial, Cachoeira do Sul, RS, Brasil. Ciência Florestal, Santa Maria, v. 14, n. 1, p. 133-147, 2004.

BERGAMIN, R. S., S. Müller, R. S. P. Melo. Indicator species and floristic patterns in different forest formation in southern atlantic rainforest of Brazil. Community Ecology. 13(2);162-170, 2012.

BORCARD, D.; GILLET, F.; LEGENDRE, P. Numerical Ecology with R. Local: Springer,
2011. 306 p.

BOLZON, R. T.; MARCHIORI, J. N. C. A vegetação no Sul da América - perspectiva paleoflorística. Ciência e Ambiente - Fitogeografia do Sul da América, Santa Maria, v.1, n.1, n.24, p. 5-24, jul. 1990.

BRASIL. Ministério da Agricultura. Levantamento de reconhecimento dos solos do Rio Grande do Sul. Recife, 1973. 431p.

BRENA, D. A.; LONGHI, S. J. Inventário Florestal da Quarta Colônia. In: ITAQUI, J. (Org.). Quarta colônia - Inventário Técnico de Flora e Fauna. Santa Maria: Condesus / Quarta Colônia. 2002. p. 34-136.

BROW, J.H. Macroecology. Chigago: University of Chigago Press. 1995

BROW, J. H., LOMOLINO, M. V. Biogeográfia. 2. ed. rev. e ampl. - Ribeirão Preto, SP: FUNPEC Editora, 2006. 691p.

BUDKE, J. C.; GIEHL, E. L. H.; ATHAYDE, E. A.; EISINGER, S. M.; ZÁCHIA, R. A. Florística e fitossociologia do componente arbóreo de uma floresta ribeirinha, arroio Passo das Tropas, Santa Maria, RS, Brasil. Acta Bot. Bras., São Paulo, v. 18, n. 3, p. 581-589, 2004.

BUDKE, J. C.; ATHAYDE, E. A.; GIEHL, E. L. H.; ZÁCHIA, R. A.; EISINGER, S. M. Composição Florística e estratégias de dispersão de espécies lenhosas em uma floresta ribeirinha, arroio Passo das Tropas, Santa Maria, RS, Brasil. Iheringia, Sér. Bot., Porto Alegre, v. 60, n. 1. p. 17-24, jan/jun. 2005.

CAVALCANTI, L. C. S. Cartografia de paisagens: fundamentos. São Paulo: Oficina de textos, 2014.

CHRISTOFOLETTI, A. Geomorfologia. São Paulo:Blucher, 2011. $13^{\circ}$ ed., pág. 188.

EMBRAPA. Sistema Brasileiro de Classificação de solo. $2^{\mathrm{a}}$ ed.; Rio de Janeiro: EMBRAPA, 2006. $306 \mathrm{p}$.

FARIAS, J. A. C.; TEIXEIRA, I. F.; PES, L.; ALVAREZ FILHO, A. A estrutura fitossociológica de floresta estacional decidual na região de Santa Maria. Ciência Florestal. Santa Maria. v. 4, n. 1, p. 109-128, 1994.

FÁVERO, A. A.; FIGUEIRA, M; ANDRIOLLO, D. D.; COSTA, M. P.; LONGHI, S. J. Florística e estrutura de uma comunidade arbórea na Floresta Estacional Subtropical. In: SEMINÁRIO SOBRE INVENTÁRIO FLORESTAL, 2., 
2011, Blumenau, SC. Annais.... Blumenau, SC: FURB, 2011.

FERRAZ, S. E. T.; ROBERTI, D. Padrões climáticos na região do extremo sul do Planalto Meridioanl brasileiro. In: SHUMACHER, M. V.; LONGHI, S. J.; BRUN, E. J.; KILKA, R. V. (Orgs.). A Floresta Estacional Subtropical: Caracterização e Ecologia no Rebordo do Planalto Meridional. [s/n], 2011, Cap. 1, p. 9-19.

GIEHL, E. L.; ATHAYDE, E. A.; BUDKE, J. C.; GESING, J. P. A.; EISINGER, S. M.; CANTODOROW, T, S. Espectro e distribuição vertical das estratégias de dispersão de diásporos do componente arbóreo em uma Floresta Estacional no Sul do Brasil. Acta Bot. Bras., São Paulo, v. 21, n. 1, p. 137-145, 2007.

GIEHL, E. L. H. Padrões estruturais e funcionais do componente arbóreo de uma floresta ribeirinha, Parque Estadual do Turvo, rio Uruguai, sul do Brasil. 2007. 64 f. Dissertação (Mestrado em Botânica) - Universidade Federal do Rio Grande do Sul, Porto Alegre, 2007.

GIEHL, E. L. H.; JARENKOW, J. A. Gradiente estrutural no componente arbóreo e relação com inundação em uma floresta ribeirinha, rio Uruguai, Sul do Brasil. Acta bot. Bras. 22(3):741753. 2008

GOTELli, N. J.; ELLISON, A. M. Princípios de estatísticas em ecologia. Porto Alegre: Artmed. 2011. $528 \mathrm{p}$.

HINTZ, M. M. Retalhos de Candelária, RS da préhistória à colonização europeia. vol.1. Gráfica ALS Schmachtenberg. 2006. 151p.

HUECK, K. As florestas da América do Sul: ecologia, composição e importância econômica; tradução de Hans Reichardt. São Paulo, Polígono, Ed. Universidade de Brasília. 1972. 458 p.

JARENKOW, J. A.; WAECHTER, J. L. Composição, estrutura e relações florísticas do componente arbóreo de uma floresta estacional no Rio Grande do Sul, Brasil. Revista Brasileira de Botânica, São Paulo, v. 24, n. 3, p. 263-272, 2001.

JURINITZ, C. F.; JARENKOW, J. A. Estrutura do componente arbóreo de uma floresta estacional na Serra do Sudeste, Rio Grande do Sul, Brasil. Revista Brasileira de Botânica, São Paulo, v. 24, n. 4, p. 475-487, 2003.

KRAY, J. G. Estrutura e estratégias de dispersão do componente arbóreo em uma floresta estacional de encosta no Parque Estadual de Itapuã. Porto Alegre: URFGS, 2010. 54 p. Dissertação (Mestrado em Botânica) - Universidade Federal do Rio Grande do Sul, URFGS, 2010.

KERN, A. A. Paleopaisagens e o povoamento préhistórico do Rio Grande do Sul. In: KERN, A. A. (Org.). Arqueologia pré-histórica do Rio Grande do Sul. Porto Alegre: Mercado Aberto, 1991.

KILCA, R. V.; LONGHI, S. L. A composição florística e a estrutura das florestas secundárias no rebordo do Planalto Meridional. In: SHUMACHER, M. V.; LONGHI, S. J.; BRUN, E. J.; KILKA, R. V. (Orgs.). A Floresta Estacional Subtropical: Caracterização e Ecologia no Rebordo do Planalto Meridional. [s/ n], 2011, Cap. 4, p. 53-83.

KLEIN, R. M. Ecologia da flora da vegetação do Vale do Itajaí. Anais botânicos do Herbário Barbosa Rodrigues. Nr. 31. 1979. Ano XXXI. $389 \mathrm{p}$.

KLEIN, R. M. Aspectos fitofisionômicos da floresta estacional na fralda da Serra Geral (RS). In: Congresso Nacional de Botância, 34, Porto Alegre. Anais ... Porto Alegre, UFRGS. 1983. Pp. $73-110$.

KLEIN, R. M. Aspectos da vegetação do Sul do Brasil. Sellowia 36: 5-54. 1984.

LEITE, P.F. Contribuição ao conhecimento fitoecológico do sul do Brasil. Ciência e Ambiente, 24: 51-73. 2002.

LINDENMAIER, D. S.; BUDKE, J. C. Florística, Diversidade e Distribuição Espacial das espécies arbóreas em uma Floresta Estacional na Bacia do Rio Jacuí, Sul do Brasil. Pesquisas Botânicas, São Leopoldo, n. 57, p. 193-216, 2006.

LINDMAN, C. A. M. A vegetação do Rio Grande do Sul (Tradução de Alberto Löefgren) Porto alegre: Universal, 1906. 356p.

Lista de Espécies do IPNI - The International Plant Names Index (2012) (http://www.ipni.org [acessado em 27 de março 2015]).

LONG.HI, S. L.; SANTOS, P.; SCHÖRN, L. A. Diferenciação dos tipos florestais do Morro Botucaraí, em Candelária, Rio Grande do Sul. Acta. For. Bras., Curitiba, v. 1, p. 99-114, 1986.

LONGHI, S. J.; NASCIMENTO, A. R. T.; FLEIG, F. D.; DELLA-FLORA, J.B.; FREITAS, R. A.; 
CHARÃO, L. W. Composição florística e estrutura de comunidades arbórea de um fragmento florestal no município de Santa Maria-Brasil. Ciência Florestal. Santa Maria, v. 9, n. 1, p. 115-133, 1999.

LONGHI, S. J.; ARAÚJO, M. M.; KELLING, M. B.; HOPPE, J. M.; MÜLLER, I.; BORSOI, G. A. Aspectos fitossociológicos de fragmento da floresta estacional decidual, Santa Maria, RS. Ciência Florestal, Santa Maria, v.10, n.2, p. 5974, 2000.

MARCHIORI, J. N. C. Dendrologia das Angiospermas: leguminosas. Santa Maria: 2. ed. UFSM, 1997. 199 p.

MARCHIORI, J. N. C.; SOBRAL, M. Dendrologia das Angiospermas: myrtales. Santa Maria: Ed. Da UFSM, 1997. 304 p.: il.

MARCHIORI, J. N. C. Fitogeografia do Rio Grande do Sul: embasamento florístico. ed. EST, Porto Alegre, 2006. 39p.

MARKUS, E.; FREITAS, E. M. Florística Arbórea de uma porção de mata de encosta do Morro Harmonia, Teutônia, Rio Grande do Sul, Brasil. Revista Pesquisas, Botânica, São Leopoldo, n. 62, p. 263-272, 2001.

MORENO, J.A. Clima do Rio Grande do Sul. Porto Alegre, Secretaria da Agricultura, 1961. 16p.

MULLER-DOMBOIS, D.; ELLENBERG, H. Aims and methods of vegetation ecology. New York: J. Wiley. 1974. 542p.

NASCIMENTO, A. R. T.; LONGHI, S. J.; ALVAREZ FILHO, A.; GOMES, G. S. Análise da diversidade florística e dos sistemas de dispersão de sementes em um fragmento florestal na região central do Rio Grande do Sul, Brasil. Napaea, Porto Alegre, v. 12, p. 49-67, 2000.

OKSANEN, J. F. G.; BLANCHET, R.; KINDT, P. LEGENDRE, R. B. O'HARA, G. L. SIMPSON, P. SOLYMOS, M. HENRY, H. STEVENS; H. WAGNER. Vegan: Community ecology package. R package version 1.17.9http:// CRAN.R-projetct. Org/package=vegan. 2010.

OLIVEIRA-FILHO, A. T. Classificação das fitofisionomias da América do Sul cisandina tropical e subtropical: proposta de um novo sistema prático e flexível ou uma injeção a mais de caos? Rodriguesia, v. 60, p. 237-258, 2009.

RAMBO, B. O elemento andino no pinhal riograndense. An. Bot. Herb. Barb. Rodr., 3(3):739, 1951a.
RAMBO, B. A imigração da selva higrófila no Rio Grande do Sul. An. Bot. Herb. Barb. Rodr., 3(3):55-91, 1951b.

RAMBO, B. História da flora do planalto riograndense. An. Bot. Herb. Barb. Rodr., 5(5):185-232, 1953.

RAMBO, B. História da flora do litoral riograndense. Sellowia, 6(6):113-172, 1954a.

RAMBO, B. S. J. A Fisionomia do Rio Grande do $\mathrm{Sul}$. Separata do volume: Fundamentos da Cultura Rio-Grandense. Primeira Série. Caderno ${ }^{\circ}$ 31. Organização: Faculdade de Filosofia Universidade do Rio Grande do Sul. 1954b.

RAMBO, P. R. A fisionomia do Rio Grande do Sul. Porto Alegre. Livraria Selbach, 1956. 456p.

RAMBO, B. Migration routes of South brazilian rain Forest. Pesquisas Série Botânica, 12: 1 - 54, 1961.

RAMBO, B. A mata pluvial do Alto Uruguai. Roessléria, Porto Alegre, 3(2): 101-139, 1980.

R DEVELOPMENT CORE TEAM R: A language and envioronmental for statistical computing R. Foundation for Statistical Computing 2012. <http://www.R-project.org> Acesso em 10 dez.2012.

REITZ, R.; KLEIN, R. M.; REIS, A. Projeto Madeira do Rio Grande do Sul. Sellowia, Itajaí, $1983,525 \mathrm{p}$.

REIS, A.; KAGEYAMA, P. Y.; REIS, M. S.; FANTINI, A. Demografia de Euterpe edulis Martius (Arecaceae) em uma Floresta Ombrófila Densa Montana, em Blumenau (SC). Sellowiana. N N 45-48. P. 13-45. 1996.

SCIPIONI, M.; LONGHI, S. J.; ARAÚJO, M. M.; REINERT, D. J. Regeneração natural de um fragmento da Floresta Estacional Subtropical Decidual na reserva biológica do Ibicui-Mirim (RS). Floresta, Curitiba, v. 39, n. 3, p. 675-690, 2009.

SOBRAL, M.; JARENKOW, J. A.; BRACK, P.; IRGANG, B.; LAROCCA, J.; RODRIGUES, R. S. A flora arbórea e arborescente do Rio Grande do Sul, Brasil. 2. Ed. São Carlos: RiMa, 2013. $357 \mathrm{p}$.

SÜHS, B. R.; PUTZKE J.; BUDKE; J. C. Relações Florístico-Geográficas na Estrutura de uma Floresta na Região Central do Rio Grande do Sul, Brasil. Floresta, Curitiba, PR, v. 40, n. 3, p. 635646, jul./set.2010.

TABARELLI, M. Flora arbórea da floresta 
estacional baixo-montana no município de Santa Maria, RS, Brasil. In: CONGRESSO NACIONAL SOBRE ESSÊNCIAS NATIVAS, 2., 1992, Piracicaba. Anais... Piracicaba: Instituto Florestal, 1992. p. 260-268.

TEIXEIRA，M. B.; COURA-NETO, A. B.; PASTORE, U.; RANGEL-FILHO, A. L. R. Vegetação, as regiões fitoecológicas, sua natureza, seus recursos econômicos, estudo fitogeográfico. In: Levantamento de Recursos Naturais, v. 33. Rio de Janeiro: IBGE. 1986. Pp 541-632.

DE MARCHI, T. C.; JARENKOW, J. A. Estrutura do componente arbóreo da mata ribeirinha no rio camaquã, município de Cristal, Rio Grande do Sul, Brasil. Iheringia, Sér. Bot. Porto Alegre. V. 63, n. 2, p. 241-248. Jul./dez. 2008.
VACCARO, S. Caracterização Fitossociológica de três fases sucessionais de uma Floresta Estacional Decidual, no município de Santa Tereza-RS. 1997. 101 f. Dissertação (Mestrado em Engenharia Florestal) - Universidade Federal de Santa Maria, Santa Maria, 1997.

VALENTIN, J. L. Ecologia numérica: uma introdução à análise multivariada de dados ecológicos. $2^{\circ}$. ed. Rio de Janeiro: Intreciência, 2012. $168 \mathrm{p}$.

VELOSO, H. P.; RANGEL FILHO, A. L.; LIMA, J. C. A. Classificação da vegetação brasileira, adaptada a um sistema universal. IBGE: Rio de Janeiro. 1991.

WAECHTER, J. L. Padrões geográficos na flora atual do Rio Grande do Sul. Ciência e Ambiente 24: 91-108. 2002. 